\title{
Religion and Peacebuilding of Citizenship
}

\author{
Bita Salafzoon \\ Center of the Research on Social Sciences, Social Sciences University of Ankara, Turkey \\ Salafzoon1982@asbu.edu.tr
}

\begin{abstract}
This concluding chapter attempts to demonstrate a potentially constructive yet under-theorized link between the scholarship and practice of peacebuilding, on the one hand, and post-colonial deconstructive tools of analysis, on the other. The latter focus on subaltern experiences and on an exposition of power dynamics (the institutional and cultural logic of misrecognition and maldistribution) illuminates two important aspects of peacebuilding: human rights advocacy and conflict transformation. The human rights framework is employed to evaluate and redress areas of injustice. It provides important vocabulary and tools with which to articulate grievances and claims of restorative justice. In tum, the transformation of a conflictual context depends on recognition of the underlying structures of injustice. Such transformative recognition may emerge out of a deconstructive introspection of the dominant ethos and patterns of control. However, for post-colonial modes of analysis and protest to affect a substantive transformation of ethnoreligious national conflict, a constructive process of reimagining the 'nation' needs to take place. This process would require reimagining alternative modes in which religion, ethnicity and conceptions of citizenship may interact with one another within the framework of the nation-state.
\end{abstract}

Keywords: Religion; Peacebuilding; Citizenship

\section{Introduction}

Hence, this concluding chapter further underscores the importance of engaging in the hermeneutics of citizenship in an effort to formulate alternative interpretations of the interrelation between nation, religion and ethnicity. Drawing on scholarship on religion and nationalism as well as recent debates about secularism, the chapter finally argues that the field of religious peacebuilding still subscribes to a modernist unrevised dichotomization of the 'religious' and the 'secular', a dichotomization which renders its activity as, at best, a supplement for the secular type of negotiations and peace work. This assumption also inhibits it from transforming the underlying root causes of a conflict, especially where conflict and acts of violence are vindicated through appeals to ethnoreligious claims(Kaldor, 1976). The first part of the chapter explicates what is meant by the hermeneutics of citizenship and why this introspective process may carry transformative potentialities to reframing ethnoreligious national ideologies, rationales for engaging in violent conflicts and the interpretations of peace and justice. The second part further explains why such a focus on the hermeneutics of citizenship may enhance and complement the theory and practice of peacebuilding. 


\section{Discussion}

This dissertation's exploration of the peace camp has shown that peace groups reinforce and reproduce Zionist historiography, Orientalism, Euro-centrism as well as the underpinning political theology of secular. Despite an apparent increased commitment to liberalism (most pronouncedly reflected in the transformation of the economy and legislations in support of broader individual liberties in the 1990s), secularism as embodied in Peace Now is nonetheless characterized by a support of the ethno-republican rationale which has defined the Israeli state since its inception in the pre-state era of colonization. This rationale suggests a commitment to the cultivation of favorable conditions for the persistence of the character of democratic nation-state. Such a commitment underwrites Smith's interpretation of the modem secular nation as a heterodox religion (Makdisi, 1978).

This process of reinterpretation may be defined as hermeneutics because it entails not only revisiting the religious and theological resources of the community through recognition of the 'ambivalence of the sacred' but also scrutinizing the modes in which the community has drawn on these resources in legitimizing its authority and actions. This is the reason why the hermeneutics of citizenship cannot take place in a historical vacuum and ask abstractly whether the selective retrieval from 'religion $\mathrm{x}$ ' to legitimate the claims of a 'nation y' is just or justifiable. But rather the hermeneutics of citizenship ought to demonstrate the degree of attentiveness to the narratives of the subaltern and their experiences of injustice. It is the overarching argument of this dissertation that when contextualized through the counter-narratives and memories of subaltern groups (with a great attention to power dynamics) and evaluated in relation to universal conventions of justice, such a scrutiny or 'hermeneutics' is effective as a transformative tool in peacebuilding(Azis \& Joebagio, 2018). This is particularly relevant in zones of conflict defined by ethnoreligious claims and modes of justification.

To this extent, it exemplifies Smith's analysis of the 'nation' as a heterodox religion. As explained in the previous chapter, Smith draws on Elie Kedourie's view of the modem nation as a secular version of Christian milleniarism in order to argue that indeed while often anti-clerical and antinomian, the secular articulation of the modem nation encapsulates and aspires for affecting the redemption of the nation or a restoration of a lost 'golden age' in this world and in historical time rather than in a metahistorical or messianic time.

Schmitt's notion of 'political theology', however, has been associated with his reactionary critique of modernity and liberalism. Accordingly, the liberal state and its constitutional framework have structurally replaced the status of God as the lawgiver, reflective in the dynamistic form of political legitimization. This transformation born of modernity and changing conceptions of political legitimacy has blocked the possibility for the sovereign to act outside the law in circumstances deemed exceptional. Thusly inhibiting the possibility of the exception became a focus of Schmitt's critique of the liberal modem democratic state articulated in his Political Theology (Friedland, 1999).

Without endorsing Schmitt's rationale for executive exceptionalism, his view of the emergence of the modem state as amounting to the secularization, yet continuous indebtedness, to its theological foundations indeed resonates with Smith's analysis of the nation as a heterodox religion. But because Smith's framework is free of the baggage that comes with Schmitt's notion of the 'sovereign' and his vehement disdain for democratic principles and practices, it provides a preferable account for challenging unrevised conceptions of the secularity of the 'nation'. Indeed, Shenhav's contention that Israeli secularity is intricately tied to religion needs to be addressed through an intricate engagement in the hermeneutics of citizenship rather than through a reclaiming and explication of sublimated theological premises and traditional forms of authority and legitimization (Chen, 1954). 
It is the engagement in the hermeneutics of citizenship where the role of religion in the interpretation of the nation is debated through an analysis of the power dynamics and subaltern memories of injustice and where the possibility of creative transformation of the conflict may emerge through an introspective reassessment of what Smith calls the 'sacred foundations' of the nation. This transformation can only be affected if the underlying root causes of the conflict are articulated and confronted. It is crucial to overcome the purified articulation of 'nation' and 'religion' as separate distinct categories and instead recognize their continuous and plastic hybridity. This recognition would enable a creative and productive hermeneutics of citizenship which may bring about a post-secular interpretation of Israeli nationalism-one that recognizes the possibility of being an Israeli and a Jew, neither by conflating nationality, ethnicity and religion nor by insisting on Jewish hegemony as a sacred principle (Sicker, 1992).

The argument goes as follows: in order to engage in the hermeneutics of citizenship, it is crucial to come to terms with the view of secular Zionism as representing a political theology and as such one which deploys the resources of tradition selectively. Such a realization opens a wide path for reinterpretations of its core motifs.

By post-secular secularity what is meant is then a shift away from a conception of the liberal secular nation-state as culturally or religiously neutral. Instead, it entails introspection of the nation's underlying political theology and/or recognition of the persistent role of religion or culture in the processes of imagining and reimagining the parameters of belonging or membership. a helpful case study because, despite its commitment to civic liberties and rights, even the liberal peace camp holds on to an ethnonational agenda reflected in a general commitment to the continuous cultivation of the idea of a Jewish and democratic nation-state. However, the self-perception of peace camp as secular and liberal presents a conceptual blinder which 'purifies' (in the Latourian sense), neutralizes and naturalizes the relevance of the ethnonational agenda to the conflict with obscures the root cause of the conflict. Hence, the liberalism is unaware or unreflective of how its illiberal commitment transpire in its conceptualization of peace and justice (Kaldor, 1976).

Undertaking an introspection of the root cause of the conflict is critical for reimagining questions of peace and justice. Such introspection forces the analyst and/or activist to connect domestic issues of social justice with broader considerations of peace and justice. As pointed by little, the more exclusivist or ethnoreligio-centric the definition of the nation is (manifested also in reduced compliance with international conventions concerning the protection of minority rights and the freedom of belief and conscience), the likelihood of international and domestic violent conflict and war increases. Little writes to this effect: "Aggressive intolerance, or the unrelenting expression of racial, religious, and ethnic superiority, has in recent experience repeatedly and unforgettably represented a potential threat of the severest kind to domestic and international peace".

Along similar lines, Ronald Thiemann's reading of John Rawls' Political Liberalism as moving away from the classical liberal myth of "the neutrality and moral transcendence of democratic government" suggests a revised view of liberalism "that might lead to a revitalization of moral deliberation within the basic institutions of American constitutional democracy". Thiemann attributes this development to Rawls' recognition "that particular notions of the good are necessary ingredients in any overlapping consensus concerning justice". Even if not explicitly, Rawls, accordingly, "has laid the groundwork for the development of a liberal conception of politics that seeks to embrace rather than transcend the pluralism of American public life" (Van der Veer, 1994).

This critique notwithstanding, both Thiemann and Casanova offer a challenge to the modernist dichotomization of the religious and the secular and subsequently attribute an important role to religious arguments in debating the character of society and political life. Casanova's attempt to rescue religion from the so-called private sphere and to demonstrate its public relevance and currency as well as Thiemann's 
revised liberalism are both potentially helpful when analyzed in relation to the question of nationalism in ethnoreligious contexts. The publicity of religion and its pertinence to public deliberations concerning the character and values of a society when viewed in relation to religion's role in imagining and legitimizing the 'nation' may contribute to the process of the hermeneutics of citizenship and affect a transformative change in the power dynamics underlying the 'state'. The crucial point here is to avoid the inclination of political theory to presuppose the 'nation' as a fixed category interchangeable with 'society' and 'state'. This would entail identifying both the power dynamics and the interpretative possibilities opened as a result of recognizing the persistent relevance of religion, culture and ethnicity to conceptions of membership in the 'nation' (Kaldor, 1976).

Indeed, when combined with the view of nationalism as a theory of political legitimacy and with the analysis of the 'nation' as consisting in a set of core beliefs, Smith's understanding of the modem secular nation as intricately but elastically related to religion provides an important point of departure for thinking constructively about the role of religion in reirnagining membership in the nation-state. Especially important to our examination here is how Smith's ethnosyrnbolist critique of modernist theories of nationalism may pertain to contemporary revised approaches to liberalism's binary distinction between the religious and the political.

Furthermore, understanding as a political theology even when its proponents interpret an ethnicity, culture or nationality rather than a religious identity has enabled our critique of liberal secularism and its modes of imagining the just resolution of conflict. It was argued that liberalism is unreflective of its underlying ethnocentricity and conceptual reliance on the basic religious themes of return, redemption and the ingathering of exiles. The recognition of the persistent role of religion in imagining the nation is indeed central to the contention that a radical restructuring of the Israeli nation-state in the interest of peace and justice would entail a hermeneutics of citizenship or reassessment of what Max Weber called the 'elective affinity' between religion, nation and ethnicity.

The process of thick recognition as articulated by Allan and Keller entails an introspection of the meanings and parameters of national identities entangled in conflict. It also calls into attention the centrality of citizenship debates and questions of domestic social justice to the analysis of broader ethno-religious national conflicts. This introspective process, it was argued, may carry far-reaching and long-term ramifications for peacebuilding because it challenges exclusivist definitions of membership through the invocation of human rights norms and subaltern critique of the dominant ethos. Hence, political theory which often accepts the 'nation' as a given variable with clear and uncontestable boundaries needs to be supplemented with insights derived from works in the study of nationalism. The latter recognizes nationalism as a theory of political legitimacy (Little) and analyzes religion as constituting an important aspect in imagining and reimagining nationhood (Smith and Marx). Finally, contemporary theorists like Asad who challenge the modernist paradigm of secularism as signaling the privatization and diminishing significance of religion in public life may be especially helpful in conceptualizing a framework for rethinking Israeli secularism as well as in conceptualizing alternative localized and context-sensitive perceptions of a identity. Therefore, integrating the emphasis of post-colonial theory on questions of power and domination with a careful engagement with the hermeneutics of citizenship may precipitate the transformation of conflicts through the emergence of alternative conceptions of peace and justice (Morgenthau, 1948).

In particular, Mertus and Helsing's latter point about the transformative potential of state institutions reverberates in conceptual efforts to apply the polycentric framework of multiculturalism as a transformative theory of justice. As discussed in this dissertation, the polycentric model of multiculturalism attributes the condition of stratified citizenship characteristic of many liberal democracies to the ethnocentricity of the 'west' which has defined itself as modem, rational and homogeneous in juxtaposition to the 'other' (the 'east') 
as ethnic, backward and irrational. As articulated by Yossi Yonah, the polycentric thread of multiculturalism attempts to debunk these binaries and reform the repressive practices which they have informed by retrieving and reclaiming subaltern view points and voices. The polycentric thread of multiculturalism identifies a close link between cultural and economic oppression endured particularly by so called ethnic minorities who reside within the confines of western liberal democracies and subsequently suggest (as seen in Fraser's work) the need to address problems of recognition and maldistribution, concurrently. In contrast to the liberal thread of multiculturalism, the polycentric approach does not focus exclusively on ensuring collective rights for minority groups within the liberal democratic framework but rather advocates the need to radically change the power dynamics. It aspires to offset the distinction between center and periphery through a transformation of the Eurocentric society into a polycentric society---a society of many centers (Smith, 1983).

Notably, while offering a penetrating critique of the Eurocentric presuppositions inherent in the liberal state and in the liberal thread of multicultural theory, the polycentric approach nonetheless holds on to universal values such as equality, recognition and mutual respect as guiding principles for its calls for the radical restructuring of the society.

Lederach is careful to distinguish the concept of conflict transformation from that of conflict resolution. He writes: "[t]ransformation includes, but is not bound by the contributions and approaches proposed by resolution-based language. It goes beyond a focus on the resolution of a particular problem or episode of conflict to seek the epicenter of conflict". To clarify, the academic field and practice of conflict resolution concentrates its resources and attention on devising immediate solutions to immediate problems. The concept of conflict transformation, on the other hand, offers a more holistic approach which views conflict as symptomatic of underlying structures and relationships. The transformation of conflict, therefore, entails a diagnosis of these core conditions and a long-term plan for reimagining the underpinning patterns which had given rise to conflict. Such a diagnostic and introspective work constitutes a form of cultural therapy and may necessitate practitioners in the field of conflict transformation to facilitate trauma healing and to devise mechanisms for engaging in processes and programs of restorative and transitional justice.

Schirch stresses the importance of linking the fields of human rights and conflict transformation precisely when programs of transitional and restorative justice are initiated to transform underlying relational patterns. In agreement with Christine Bell's work, she explains that human rights norms provide standards for evaluating the legitimacy of diplomatic efforts to transform conflict. Further, the documentation of human rights abuses during the time of conflict offers a tangible and indisputable record to contend with in the process of redressing the past as an integral part of peace negotiations and settlements. Similarly, the human rights approach supports conflict transformation processes which include a careful consideration of offenders' perceptions of injustice. The inclusion of human rights offenders in peace negotiations is crucial. It is also crucial, however, to deploy human rights standards as an evaluative framework which enables public accountability for offenses and demands for restitution.

Lederach' s approach to conflict transformation as a multidimensional process that studies the dynamics of an immediate problem as well as explores the deeper relational patterns or root causes of conflict in an attempt to connect the two sites of inquiry in a constructive and transformative way, attentive both to the urgency of an immediate episode as well as to its epicenter. This understanding of conflict transformation resonates with the analysis of the Israeli peace camp presented in this dissertation (Hunt, 1980).

Recognizing those links does not only provide an explanatory framework for understanding the important yet overlooked interconnectedness between 'domestic'social justice issues. An exploration of those links and their relevance to the history of the conflict also suggests itself as a key for reframing and 
transforming what Lederach calls the underlying relational patterns and thus as a key for developing a conceptual framework for transforming conflict.

This section is titled "religion: the missing dimension of peacebuilding" to first underscore that while religion has increasingly been recognized as a factor in peacebuilding, religious movements such as RHR have failed to engage in the hermeneutics of citizenship thereby accepting the political theology of the ethno- republican nation-state as axiomatic. Second, the new field of inquiry and practice of 'religion in peacebuilding' too overlooks the importance of introspecting the nexus between religion, nationalism and ethnicity as articulated and reproduced in zones characterized by ethnonational conflicts. This critique derives from this work's recognition of (1) the persistent role of religion in the processes of imagining and reimagining the nation as suggested in Anthony Smith's work on nationalism, (2) the potentially transformative and liberalizing role of 'state' institutions inmoving away from exclusivist interpretations of nationhood toward increased inclusivity which,according to Anthony Marx's study, has been the case in western Europe, (3) David Little and Scott Appleby's notion of the ambivalence of the sacred and the irreducibility of the resources of religion to interpretations of nationalism, despite what might be suggested by nationalist rhetoric and (4) ongoing theoretical conversations which have challenged modernist interpretations of the 'secular' as representing the absence or diminishing presence of religion and as subsequently implying a neutral public sphere.

Subsequently, what is proposed is a long-term and multidimensional process of peacebuilding and conflict transformation which, as defined by Schirch, would pursue "[a] deeper transformation of structures, paradigms, cultures, and values ..." This multidimensional process certainly draws on discourse's application of post-colonial tools to deconstruct the hegemonic ethos and on the explicit appeal of the "Vision" to international norms of human rights as an empowering vehicle for the advancement of programmatic proposals for institutional restructuring, including attentiveness to the demands of for economic, political, civil and cultural rights (Swedenburg, 1995).

Our examination of the two cases of the Vision and the Keshet has suggested that the two key aspects of the hermeneutics of citizenship are, firstly, a contextualization of identities and exploration of the power dynamics which define their relationships and, secondly, developing a nuanced post-secular secularism which acknowledges the enduring bearing of religion on public life and articulation of identity and in reimagining the definition of citizenship along more inclusivist and polycentric lines. Neither the Keshet nor the Vision, however, moves beyond a modernist interpretation of the secular and the religious as dichotomous. Their reliance on this basic modernist binary prevents the possibility of engaging in a substantive reassessment of the relation between Judaism, Israeliness and the dynamics of citizenship.

However, our scrutiny of the Keshet and the Vision has suggested one central obstacle to extrapolating from their models a comprehensive framework for peacebuilding and conflict transformation in ethno-religious national contexts. This hurdle relates to their evasion of the question of the role of religion in the process of reimagining the Israeli 'nation' and the meanings and parameters of belonging to the 'state'. In the case of the Vision, the interrelation is rendered problematic and in contradiction to human rights norms. Thus, the Vision stresses the need to overcome this conflation between religion and nation by relegating religion to private or autonomous spheres and by ensuring the end of public manifestations of symbolic, socioeconomic and political superiority. This objective, however, cannot be attained solely by citing and dictating international legal norms but rather the appropriate relation between religion and nation (Gurr, 1993).

"A comprehensive peace based solely on secular values, actors, and frameworks will not be sustainable; peace must involve the religious believers and resonate with their faith". The latter further argue that the practice of interfaith Dialogue (IFD) may contribute significantly to the processes of peacebuilding and conflict transformation by highlighting the transformative qualities of its model of confession and 
forgiveness. Accordingly, if a demand for an ethic of self- criticism is cultivated, the IFD framework may facilitate transformative moments of confession and forgiveness when the interlocutors recognize and acknowledge their moral responsibility for instances of injustice associated with their faith and when they find equal courage to forgive (but not forget) acts of violence perpetrated against them.

Schirch similarly underscores the transformative aspects of dialogue by focusing on the power of common rituals practiced by those engaged in a dialogue and their capacity to symbolically transform identities and reframe the conflict in a ritualized form.

This approach to IFD however assumes an unrevised interpretation of the 'secular' as a neutral category devoid of religion, an assumption that constrains the relevance of religion to the hermeneutics of citizenship or the introspective process of reimagining the complex interrelation between religion, nation and ethnicity. While the field of religious peacebuilding is focused primarily on the practice of IFD as constituting an important and potentially transformative aspect of peacemaking and reconciliation, its dependence on the secularist paradigm limits its effectiveness. Our reliance on a synthesis of Marx's and Smith's approaches to the study of nationalism underscores the persistent relevance of religion to the formation and reformation of national identity. Subsequently, the resources of religion and tradition are especially relevant in cases defined by ethnoreligious agenda and rhetoric. In the case of Israel, such introspection of the role of religion would entail a substantive examination of the political theology undergirding secular (Luz, 1988).

\section{Conclusion}

Likewise, it was argued that while presenting a challenge to the ambivalent treatment of religion by mainstream secularism, the religious peace camp has reinforced the general contours of the latter's underlying political theology. In other words, our study of a group such as Rabbis for Human Rights has first demonstrated an ahistorical interpretation of the right of Jewish return to the land of Palestine. This interpretation is ahistorical or metahistorical to the extent that it overlooks how historical details such as the presence of another group of people in the land may constrain and limit this motivation to act upon a messianic impulse. A historically contextualized analysis of this movement of return may categorize it as colonialist. This is despite the special place and the concept of return have indeed occupied in the imagination over millennia of diasporic life.

While the religious peace movement has accepted and reinforced the political theology undergirding the ideology of secular, the growing scholarship and field of practice which identifies religion as a valuable dimension of peacebuilding and conflict transformation has subscribed to a modernist understanding of the 'religious' and the 'secular' as occupying distinct realms. In other words, the scholarship on religion and peace does not consider how the insights of recent debates on secularism may bear on its analytical and practical understanding of the role of religion in peacebuilding. Nor has it incorporated the insistence of post-colonial theory on reassessing the core beliefs of the 'nation' from the point of view of its subalterns. Religious peacebuilding has thus been relegated to the sphere of diplomacy as an auxiliary (albeit a necessary one) to the secular framework of official negotiations. As stated by Abu Nimer et al. in a recent work on the topic of interfaith dialogue. 


\section{References}

Azis, A., \& Joebagio, H. (2018). International Journal of Multicultural and Multireligious Understanding Correlation between : Understanding of Nationalism and Historical Consciousness toward Students , Democratic Attitude in Banda Aceh Senior High School. 60-71.

Chen, B. (1954). The Chief Rabbinate in Israel. Jerusalem: Ministry of Religious Affairs.

Friedland, R. (1999). When God Walks in History: The Institutional Politics of Religious Nationalism. International Sociology, 14(3), 301-319. https://doi.org/10.1177/0268580999014003005

Gurr, T. D. (1993). Minorities at Risk: A Global View of Ethnopolitical Conflicts. Washington, D.C: Institute of Peace.

Hunt, C. and L. H. (1980). Sociology (Fifth Edit). New York: McGraw-Hill.

Kaldor, M. (1976). The military in development. World Development, 4(6), 459-482. https://doi.org/10.1016/0305-750X(76)90032-2

Luz, E. (1988). Parallels Meet: Religion and Nationalism in the Early Zionist Movement (1882-1904). In 1988. Philadelphia: Jewish Publication Society.

Makdisi, S. a. (1978). Flexible exchange rate policy in an open developing economy: The Lebanese experience, 1950-1974. World Development, 6(7-8), 991-1003. https://doi.org/10.1016/0305$750 \mathrm{X}(78) 90057-8$

Morgenthau, H. J. (1948). Politics Among Nations. New York: Mc Graw-Hill.

Sicker, M. (1992). Judaism, Nationalism and the Land of Israel. Boulder, San Francisco and Oxford: Westview Pres.

Smith, A. D. (1983). Theories of Nationalism. New York: Holmes \& Meier Publisher.

Swedenburg, T. (1995). Memories of Revolt. Minneapolis: University of Minnesota Press.

Van der Veer, P. (1994). Nation and Religion: Perspectives on Europe and Asia (H. Lehmann, ed.). Princeton, N.J: Princeton university press.

\section{Copyrights}

Copyright for this article is retained by the author(s), with first publication rights granted to the journal.

This is an open-access article distributed under the terms and conditions of the Creative Commons Attribution license (http://creativecommons.org/licenses/by/4.0/). 